\title{
An Analysis of Blood Donating Rate in Australia, Influential Factors and Recommendations to Increase the Rate
}

\author{
Xinyuan Zheng \\ Correspondence: Xinyuan Zheng, 13 Fonti Street, Eastwood, NSW, Sydney, Australia. Tel: 4-1661-8518. \\ Received: October 11, 2019 \\ Accepted: November 4, 2019 \\ Online Published: November 6, 2019 \\ doi:10.20849/ajsss.v4i4.667 \\ URL: https://doi.org/10.20849/ajsss.v4i4.667
}

\begin{abstract}
Based on the information from the research of the red cross, it can be known there is a low value for the average blood donating rate in Australia, which is around 3\%, which means the population for the blood donating are more insufficiency, it may lack of the blood in the blood bank for the injured person use, especially in the emergency such as earthquake, traffic and so on. Consequently, there is no doubt that the quantity of blood and the amount of blood donor need be increased in Australian Red Cross (ARCBS).

The purpose of this group assignment is to analysis the survey data that provided, find the server relevant questions about the blood donating, using the SPSS software and reasonable test to examine them. For instance, find the relevant information about donating such as whether the male or female more frequency to donating blood, the possible reason of people choose to donating blood, the reason of the donators encourage their friends and family to donate blood, which publication are more effective, the personally or the media appeal and so on. Finally, it will provide several suitable solutions and reasonable recommendations to ARCBS based on the test results and answer of the questions, in order to help the ARCBS broaden the blood donor base.
\end{abstract}

Keywords: SPSS, income, gender, education, feeling, donating processing

\section{Question Analyzing}

\subsection{Question 1}

What is the degree of importance of hindering people from donating blood due to the uncomfortable feeling in the process of blood donation?

The Time-course of Emotion in Donation (TED) approach is used to determine how the emotional experience of blood donors in different time-points impacts donor behavior (Williams et al., 2017). In terms of the negative emotions such as the discomfort in the process of blood donation, it is worth to discuss that whether it can be the factor of hindering people from donating blood.

\subsubsection{Variable Used}

The uncomfortable feeling of people in the process of blood donation (Q4a1).

\subsubsection{Statistical Test Conducted}

Descriptive statistics

\subsubsection{Analysis \& Findings}

According to the frequency table in appendix 2, the mode in the statistic table is 5 which means the 5 group is related to the most observations. In the one-way frequency table, it is obvious that the largest number in the Frequency column is 174 relating to the 5 group. Besides, from the Valid Percent column, the sum of the proportion of 5, 6 and 7 group is $58.9 \%(23.1 \%+18.7 \%+17.1 \%)$ which is accounts for more than the half of overall non-missing observations.

\subsubsection{Managerial Implications / Recommendations}

In the one-way frequency table, the number in the first line which is interval variable shows the degree of importance of hindering people from donating blood due to the uncomfortable feeling in the process of blood donation. The 5, 6 and 7 group of which the sum occupies more than half of the observations represent that the uncomfortable feeling in the process of blood donation is an important reason for most people not to donate blood. Therefore, it is suggested to provide a more comfortable environment for people and improve the 
experience of blood donation and then people may not resist donating blood as before.

\subsection{Question 2}

When people donate blood, do they prefer accompanying by their friends than coming alone?

A previous research found that the friends' behavior of donating blood may stimulate people to donate blood in the future (Lindenmeier \& Tscheulin, 2005). Thus, the influence of friends for blood donation behavior could be significant and the effect of accompanied by friends for blood donors could be discussed.

\subsubsection{Variable Used}

Accompanying by friends (Q2c6).

Donating blood alone (Q2c7).

\subsubsection{Statistical Test Conducted}

Paired-sample test

\subsubsection{Analysis \& Findings}

The hypothesis test could be set as

H0: When people donate blood, they prefer coming alone than accompanying by their friend. $\left(\mu \_\mathrm{Q} 2 \mathrm{C} 6 \leq \mu_{-} \mathrm{Q} 2 \mathrm{c} 7\right)$

Ha: When people donate blood, they prefer accompanying by their friends than coming alone. $\left(\mu \_\mathrm{Q} 2 \mathrm{C} 6>\mu \_\mathrm{Q} 2 \mathrm{c} 7\right)$

Firstly, in the paired samples statistics table in appendix 2, the mean of Q2c6 which is 4.41 is greater than the mean of Q2c7 which is 2.82. Moreover, when the amount of the sample units is more than 30, z-test should be used (Surbhi, 2018). The z-test is used because the overall observations are 753 which is more than 30 . According the appendix 1, the critical test value is 1.645 in the $95 \%$ confidence interval. Comparing with the calculated test value which is shown as 18.171 in the paired samples test table, the critical test value is less than the calculated test value. In addition, the p value calculated by SPSS is $0.000(0.000 / 2)$ which is less than 0.05 . In conclusion, the null hypothesis should be rejected which means that the null hypothesis is wrong, and people prefer accompanying by their friends than coming alone when they donate blood.

\subsubsection{Managerial Implications / Recommendations}

From the rejection of null hypothesis and the comparison of means between Q2c6 and Q2c7, more people agree that they prefer accompanying by their friends than coming alone when they donate blood. Therefore, the Australian Red Cross could advertise aiming to meeting places and social media websites to encourage people donating blood accompanied by their friends. By this means, they could donate blood continually and their friends may join them and donate blood together.

\subsection{Question 3}

Is the likelihood that people encourage their friends and families to donate blood in Australia associated to people's concern about contracting illness through the donation process?

A research about the reason that female does not donate blood found the most widespread misconception is that respondents are concerned about contracting diseases such as AIDS and hepatitis (Bilal et al., 2015). Therefore, the correlation between the fear of contracting illness in the process of donating blood and the likelihood that people encourage others to donate blood will be discussed.

\subsubsection{Variable Used}

People's concern about contracting some illness through the donation process (Q4a4).

The likelihood that people encourage their friends and family to donate blood in Australia (Q1f).

\subsubsection{Statistical Test Conducted}

\section{Correlation analysis}

\subsubsection{Analysis \& Findings}

The hypothesis test could be set as

H0: The likelihood that people encourage their friends and families to donate blood in Australia is not associated to people's concern about contracting illness through the donation process. (correlation coefficient $\rho=0$ ) 
Ha: The likelihood that people encourage their friends and families to donate blood in Australia is associated to people's concern about contracting illness through the donation process. (correlation coefficient $\rho \neq 0$ )

In the correlation table in appendix 2, two asterisks are marked as there is a 0.01 significance level (Verma, 2016). Besides, $\mathrm{p}$ value is 0.000 which is less than 0.01 . Thus, the null hypothesis should be rejected and the likelihood that people encourage their friends and families to donate blood in Australia has a statistically significant linear relationship with people's concern about contracting illness through the donation process. Moreover, because the Pearson correlation -0.240 is less than zero, the two variables are in negative linear correlation. Furthermore, the Pearson correlation -0.240 is between -0.40 and -0.21 , for that reason, the association is approximately weak.

\subsubsection{Managerial Implications / Recommendations}

According to SPSS statistics, the likelihood that people encourage their friends and families to donate blood in Australia reduces with the increasing of people's concern about contracting illness through the donation process. Consequently, in order to broaden blood donor base in Australia, it is essential for the Australian Red Cross to introduce the process of donating blood to the public to remove misconceptions that blood donors have risk for contracting illness through the process. The use of the major source of information such as social media and mobile applications could increase the public's knowledge and concern about donating blood.

\subsection{Question 4}

What elements would influence the likelihood that people analyses would encourage their friends and family in Australia to donate blood?

Donor recruitment, retention and their advocacy are significant problems in blood collection agencies worldwide. A Finding showed that most important factors which caused the idea of not being able to donate blood were related to the lack of information about physical condition (67\%), physical weakness (59.3\%), diseases (52.3\%), malnutrition (51.5\%) and inaccessibility to donation bases (51\%) and so on (M T Shakeri, 2012). It said more than $69 \%$ of participants thought the blood donation may endanger their health and more than $67 \%$ of them did not know much about the blood donation process (M T Shakeri, 2012). Therefore, would we like to use SPSS to analyses is these elements do matter the blood donation?

\subsubsection{Variables Used}

\section{Dependent variable:}

How likely would you be to encourage your friends and family in Australia to donate blood? (Q1f)

\section{Independent variables:}

My concern that I will contract some illness through the donation process. (Q4a4)

My concern that I would feel weak or unwell afterwards. (Q4a5)

The inconvenience of needing to go to the blood donation facilities. (Q4a10)

My lack of concern about the need for blood. (Q4a14)

\subsubsection{Statistical Test(s) Conducted}

Regression analysis

\subsubsection{Analysis \& Findings}

The model has a lower $\mathrm{R}$ square which means the less the dependent variables is associated with the independent variable, while from the ANOVA test, the model is considered to be significant due to the $0 \mathrm{P}$-value so there is liner relationship between dependent and independent variables. Based on findings in coefficients, it is distinct that $4 \mathrm{a} 4$ and $4 \mathrm{a} 14$ can be considered as significant factors because of the $0 \mathrm{P}$-value. The value -0.157 and -0.153 indicate the causality between dependent and independent variables and the negative direction of the liner relationship. That is, an increase in concern that people may contract some illness through the donation process will lead to the decreased possibility that participates encourage their friends and family to donate blood in Australia. Moreover, lack concern of the blood needing will also hinder participates encourage their friends and family to donate blood. However, an increase with the blood donation facilities convenience will lead participates positively encourage blood donation to their friends and families.

\subsubsection{Managerial Implication / Recommendations}

This test identifies the main hindrance that effects on blood donation advocacy. Firstly, the reason why participates don't donate blood and not encourage people surrounding is due to the concern that they may infect 
some illness (4a4). Aiming at this, ARCBS could disseminate the process of donating, emphasizing the blood is collected through a new, sterile needle that is used once and then discarded, and the donation facilities are required to maintain the standard of sanitation in Australia. Moreover, ARCBS also has the duty to popularize the need of blood (e.g. by letting people who need blood share their story with others) as lacking the basic knowledge of blood needing is considered as one factor that people will not encourage others to donate. It seems that the methods of blood transfer organizations should promote the knowledge of people about blood donation. The blood donors are informative references for others, and they can attract new donors (Rahav, 2017). Thus, education of programs is recommended for heightening awareness.

In addition, the data reflects that inconvenience donation facilities make it hard to donate blood. If ARCBS has enough budget, boost the development of the blood donation facilities should also be considered.

\subsection{Question 5}

Would we like to analyses for people who had the experience of giving time or money to charity, what external stimulus will encourage the blood donation?

In another study, participants who had a time when they purchased something for someone else/giving something to others felt happier than those who recalled spending money on themselves, it suggests there is a feedback loop between happiness of giving and generosity (Aknin, 2012). Therefore, we would like to analyses for people who had the experience of giving time or money to charity, what external stimulus will encourage the blood donation?

\subsubsection{Variables Used}

Dependent variable:

In a typical year, how frequently do you give time or money to charity? (Q5b)

Independent variables:

My desire to give back to the community. (Q3b2)

The pressure I feel from others to donate. (Q3b6)

Receiving an incentive or reward for donating. (Q3b10)

Knowing someone who has received blood. (Q3b14)

\subsubsection{Statistical Test(s) Conducted}

Regression analysis

\subsubsection{Analysis \& Findings}

When dealing with this dataset, initially, we need to convert the dependent variable (Q5b) from string data into numerical data (i.e. Never is 0 , Once or twice is 1, 3-5 times is 2 and such on). This model also has a very low $\mathrm{R}$ square which leads to a small effect size and 0 P-value in ANOVA test shows there is liner relationship between dependent and independent variables.

According to the value of coefficient analysis, all those four variables is significant as they all with the approximately $0 \mathrm{P}$-value. The desire to give back to the community and knowing someone who has received blood do encourage the people who had the experience of giving time or money to charity to donate blood (positive linear relationship). Additionally, the interesting thing is that those type of people will decrease their interests in donating blood if they will receive an incentive or reward from donating, or they feel the pressure from others to push them to donate (negative linear relationship).

\subsubsection{Managerial Implication/ Recommendations}

According to the SPSS result, participates especially who has the experience give time or money to charity is affected by their desire to giving back to the community and by the knowing with someone who has been donated before. ARCBS could then promote blood donating by letting some people who has been donated before to share their stories in front of some charities, tell the donator how their donation is helpful. One study found that, across three different experiments, adding tangible details about a charity's interventions increased donations because these details increased the participants' belief that their generosity could have an impact on a particular problem (Loewenstein and Scheines, 2012). Moreover, ARCBS should mention it is a non-profit activity and it just pursues the meaning of giving back to the community. 


\subsection{Question 6}

Have females donate blood more frequently than males within Australia in the last two years?

It has been mentioned that there is limit study of gender differences towards the blood donation and it would be helpful for both the donors and the ARCBS to improve the process of blood donation and widen the blood donor base (Bala, Handoo \& Jallu, 2015). Thus, the following question has been raised for analysis.

\subsubsection{Variables Used}

Dependent variables:

Frequency of donating blood within Australia in the last two years? (Q1b)

Independent variables:

Gender (Q7a)

1.6.2 Statistical Test(s) Conducted

Independent-Samples T-test

1.6.3 Analysis \& Findings

The hypothesis can be set as:

$\mathrm{H}_{0}$ : There is no gender difference towards the frequency of blood donation within Australia in last two years.

$\mathrm{H}_{\mathrm{A}}$ : There are gender differences towards the frequency of blood donation within Australia in last two years.

From the table of independent sample test in appendix 2, it can be found that the p-value is 0.008 , which is smaller than the critical value 0.05 . Therefore, the null hypothesis should be rejected since there is sufficient evidence to prove that the null hypothesis is incorrect. It can be concluded that there are differences between males and females towards the blood donation that males donated blood more frequently than females in Australian in last two years. Based on the means shown in the data, it can be seemed that males make more donations of blood than females, though both of them did not donate blood for many times within Australia in the last two years.

\subsubsection{Managerial Implications / Recommendations}

This test confirms the differences of the frequency blood donation between men and women in Australia in last two years. It is stated that this result is similar as the result of research made in the other countries, such as America (Bani \& Giussani, 2010). It has been found that the potential reasons for females having a lower frequency of blood donation involve their possible pregnancies and their lower weight than men, which make them be afraid of getting mild anemia after blood donations. Also, the higher frequency of men's blood donation might be influenced by special circumstances, including that they are from military. However, it was shown that the gender differences towards the frequency of blood donation in Australia should be not as severe as in the other countries, which means males and females made blood donation in Australia in similar proportion (Bala, Handoo \& Jallu, 2015). This implies that the survey is not precise enough to study the gender difference for the frequency of donating blood while the sample size is not large enough and the age range of people who did the survey is too limit. In addition, because of the limit research of gender difference, the ARCBS could focused more on the gender field so as to find solutions to those potential reasons that prevent people from donating blood and effectively improve the frequency of blood donation for people in Australia.

\subsection{Question 7}

Do people have a significant attitude for blood donation towards their self-responsibilities?

The debate of whether the material rewards or prosocial motivations would improve the blood donor base had been mentioned a lot for several years (Abolghasemi H, Nasim. S \& Segihali. F, 2010). In order to prove that the ethical motivation strongly stimulate people to make blood donation, the following question has been raised.

\subsubsection{Variables Used}

Knowing I am potentially saving a life would be a factor to motivate you to donate blood in Australia. (Q3b11)

\subsubsection{Statistical Test(s) Conducted}

One Samples t-test

\subsubsection{Analysis \& Findings}

The hypothesis test could be set as 
$H_{0}$ : Self-responsibilities will not affect people to donate blood in Australia.

$H_{A}$ : Self-responsibilities will affect people to donate blood in Australia.

According to the data in one sample test from appendix 2, it can be seemed that the p-value is 0.000 , which is less than the critical value 0.05 . Therefore, there is significant evidence to prove that the null hypothesis is incorrect and should be rejected. In addition, the mean for the testing variable is 5.46, which is very close to the strongest attitude. As a result, it is shown that people have strong attitude toward their self-responsibility for blood donation in Australia and there would be high possibilities for them to donate blood while they know that they are potentially saving live.

\subsubsection{Managerial Implications / Recommendations}

The test identifies that the motivation of saving life for donors is extremely important. This result is converse to the hypothesis, which is that people would be highly motivated by material rewards. It has been stated that a physical remuneration for blood donors might not encourage them to make more blood donation but even destroy their willingness to donate blood (Stutzer \& Goette, 2010). Donors would consider taking material rewards as immoral actions since most of them donated blood on a voluntary basis. Based on the data analysis, the ARCBS could focus on disseminating the consequence after blood donation, which is that more people would be saved with more blood donation, to the public to stimulate people's self-responsibilities to donate blood.

\section{Recommendation}

On the basis of above survey data analysis, there are some recommendations for ARCBS about the content and target group of future blood donating propaganda and the need to improve their service quality.

Firstly, when broadcasting the benefit of blood donation, ARCBS should focus more on the altruism factors such as inspiring the desire to give back to community and emphasizing the nature of non-profit activity as well as the lack of blood. As such factors are positively related to the incentives of people to give time or money to charity, this positive effect can apply to encourage more people to donate blood.

In addition, based on the questions and the test results from the previous section, it can be known the male donating blood is more frequency then female, and personally publication is more effective then media appeals. Therefore, for the target group of the future blood donating propaganda, it should strengthen the propaganda within male donators and increase the broadcasting power on female, also it should enhance the personally publication method for the broadcasting the benefit of blood donation.

Moreover, the ARCBS should improve their service quality. If the environment of the donating blood is insanitation, it may make the donators contract some illness through the donation process, consequently, the ARCBS should ensure their work place for the donating process is clean, sanitary and safety, this action can reduce the apprehension from the donators about they may contract the illness through the donating blood. Additionally, the ARCBS can create a relaxed donating environment for the donators, such as leaving the TV on or playing relaxing music may reduce their stress, and prepare some snack food such candies, chocolate for donators after the donation process. Furthermore, providing higher quality services for the donators can make them have the better donation experience, and increase the probability of they encourage their friends or family to donating blood, thus broaden the blood donor base.

\section{Limitation}

\subsection{Collected Data Is Lack of Representation}

Based on the information that can be collected from the survey, the age group of the respondents to the survey is very narrow, from 18 to 37 and there are only 763 people as the analyzed sample, which is not a standard sample to analysis how to broaden blood donors in Australia. Such an unrepresentative dataset raises difficulty in quantitative analysis and reduces the reliability of output because the poor data damaged the likelihood of model to be significant such as the low R square in every regression model.

\subsection{Fewer Demographic Related Questions Within the Survey}

The ARCBS is concerned about that the current demographics of blood donors are not representative of general population, but the survey was designed to have fewer demographic questions such as education level, income level and occupation, which provides less information for analysts to identify the relations between these variables and reasons why people refuse to donate blood.

For example, people with higher educational status are more likely to donate blood and educational status is also 
positive related with the income level of blood donors (Gillespie, 2002). But such correlations that may provide good solutions to increase blood donors in Australia fail to be tested because the lack of data in the survey related to educational status and income level.

\section{References}

Abolghasemi, H., Nasim, S., \& Segihali, F. (2010). Blood Donor Incentives: A Step Forward or Backward. Journal of Transfusion Science, 4(1), 9-13. https://doi.org/10.4103/0973-6247.59385

Aknin, L. B., Dunn, E. W., \& Norton, M. I. (2012). Happiness Runs in a Circular Motion: Evidence for a Positive Feedback Loop between Prosocial Spending and Happiness. https://doi.org/10.1007/s10902-011-9267-5

Bala, S., Handoo, S., \& Jallu, A. (2015). Gender Differences in Blood Donation among Donors of Kashmir Valley. $\quad$ Retrieved from http://www.iosrjournals.org/iosr-jdms/papers/Vol14-issue2/Version-1/X01421116119.pdf

Bilal, M., Haseeb, A., Zahid, I., Lashkerwala, S., Saeeduddin, F., Saad, M., ... Bilal, M. (2015). Knowledge, attitudes and perceptions among non-blood donor female health care professionals. Global Journal of Health Science, 8(4), 203-211. https://doi.org/10.5539/gjhs.v8n4p203

Gillespie, T. W., \& Hillyer, C. D. (2002). Blood donors and factors impacting the blood donation decision. Transfusion Medicine Reviews, 16(2), 115-130. https://doi.org/10.1053/tmrv.2002.31461

Lindenmeier, J., \& Tscheulin, D. (2005). The willingness to donate blood: an empirical analysis of socio-demographic and motivation-related determinants. Health Services Management Research, 18(3), 165-174. https://doi.org/10.1258/0951484054572547

Loewenstein, G., \& Scheines, R. (2012). Organizational Behavior and Human Decision Processes. Retrieved 28 May 2019, from https://www.cmu.edu/dietrich/sds/docs/loewenstein/DonorInDetails.pdf

Rahav Koren, R., Suriu, C., Yakir, O., Akria, L., Barhoum, M., \& Braester, A. (2017). Physicians' lack of knowledge - a possible reason for red blood cell transfusion overuse?. Israel Journal of Health Policy Research, 6(1), 49. https://doi.org/10.1186/s13584-017-0173-0

Shakeri, M. T., Vafaee, A., Esmaeily, H., Shafiei, N., Bazargani, R., \& Khayamy, M. E. (2012). The Causes for Lack of Interest to Blood Donation in Eligible Individuals, Mashhad, Northeastern Iran. Iran Red Crescent Med J., 14(1), 37-40. Retrieved $25 \quad$ May 2019, from https://www.ncbi.nlm.nih.gov/pmc/articles/PMC3372016/

Stutzer, A., \& Goette, L. (2010). Blood Donor Motivation: What is Ethical? What Works?. https://doi.org/10.1111/j.1751-2824.2010.01378.x

Surbhi, S. (2018). Difference Between T-test and Z-test. Retrieved from https://keydifferences.com/difference-between-t-test-and-z-test.html

Verma, J. (2016). Sports research with analytical solution using SPSS. Hoboken, New Jersey: John Wiley \& Sons Inc. https://doi.org/10.1002/9781119206767

Williams, L., Masser, B., Van Dongen, A., Thijsen, A., \& Davison, T. (2018). The emotional psychology of blood donors: a time-course approach. ISBT Science Series, 13(1), 93-100. https://doi.org/10.1111/voxs.12385 


\section{Appendix}

Appendix 1

Numbers in each row of the table are values on a $t$-distribution with $(d f)$ degrees of freedom for selected right-tail (greater-than) probabilities ( $\rho$ ).

\begin{tabular}{|c|c|c|c|c|c|c|c|c|}
\hline $\mathrm{dt} / \mathrm{p}$ & 0.40 & 0.25 & 0.10 & 0.05 & 0.025 & 0.01 & 0.005 & 0.0005 \\
\hline 1 & 0.324920 & 1.000000 & 3.077684 & 6.313752 & 12.70620 & 31.82052 & 63.65674 & 636.6192 \\
\hline 2 & 0.288675 & 0.816497 & 1.885618 & 2.919986 & 4.30265 & 6.96456 & 9.92484 & 31.5991 \\
\hline 3 & 0.276671 & 0.764892 & 1.637744 & 2.353363 & 3.18245 & 4.54070 & 5.84091 & 12.9240 \\
\hline 4 & 0.270722 & 0.740697 & 1.533206 & 2.131847 & 2.77645 & 3.74695 & 4.60409 & 8.6103 \\
\hline 5 & 0.267181 & 0.726687 & 1.475884 & 2.015048 & 2.57058 & 3.36493 & 4.03214 & 6.8688 \\
\hline 6 & 0.264835 & 0.717558 & 1.439756 & 1.943180 & 2.44691 & 3.14267 & 3.70743 & 5.9588 \\
\hline 7 & 0.263167 & 0.711142 & 1.414924 & 1.894579 & 2.36462 & 2.99795 & 3.49948 & 5.4079 \\
\hline 8 & 0.261921 & 0.706387 & 1.396815 & 1.859548 & 2.30600 & 2.89646 & 3.35539 & 5.0413 \\
\hline 9 & 0.260955 & 0.702722 & 1.383029 & 1.833113 & 2.26216 & 2.82144 & 3.24984 & 4.7809 \\
\hline 10 & 0.260185 & 0.699812 & 1.372184 & 1.812461 & 2.22814 & 2.76377 & 3.16927 & 4.5869 \\
\hline 11 & 0.259556 & 0.697445 & 1.363430 & 1.795885 & 2.20099 & 2.71808 & 3.10581 & 4.4370 \\
\hline 12 & 0.259033 & 0.695483 & 1.356217 & 1.782288 & 2.17881 & 2.68100 & 3.05454 & 43178 \\
\hline 13 & 0.258591 & 0.693829 & 1.350171 & 1.770933 & 2.16037 & 2.65031 & 3.01228 & 4.2208 \\
\hline 14 & 0.258213 & 0.692417 & 1.345030 & 1.761310 & 2.14479 & 2.62449 & 2.97684 & 4.1405 \\
\hline 15 & 0.257885 & 0.691197 & 1.340606 & 1.753050 & 2.13145 & 2.60248 & 2.94671 & 4.0728 \\
\hline 16 & 0.257599 & 0.690132 & 1.336757 & 1.745884 & 2.11991 & 2.58349 & 2.92078 & 4.0150 \\
\hline 17 & 0.257347 & 0.689195 & 1.333379 & 1.739607 & 2.10982 & 2.56693 & 2.89823 & 3.9651 \\
\hline 18 & 0.257123 & 0.688364 & 1.330391 & 1.734064 & 2.10092 & 2.55238 & 2.87844 & 3.9216 \\
\hline 19 & 0.256923 & 0.687621 & 1.327728 & 1.729133 & 2.09302 & 2.53948 & 2.86093 & 3.8834 \\
\hline 20 & 0.256743 & 0.686954 & 1.325341 & 1.724718 & 2.08596 & 2.52798 & 2.84534 & 3.8495 \\
\hline 21 & 0.256580 & 0.686352 & 1.323188 & 1.720743 & 2.07961 & 2.51765 & 2.83136 & 3.8193 \\
\hline 22 & 0.256432 & 0.685805 & 1.321237 & 1.717144 & 2.07387 & 2.50832 & 2.81876 & 3.7921 \\
\hline 23 & 0.256297 & 0.685306 & 1.319460 & 1.713872 & 2.06866 & 2.49987 & 2.80734 & 3.7676 \\
\hline 24 & 0.256173 & 0.684850 & 1.317836 & 1.710882 & 2.06390 & 2.49216 & 2.79694 & 3.7454 \\
\hline 25 & 0.256060 & 0.684430 & 1.316345 & 1.708141 & 2.05954 & 2.48511 & 2.78744 & 3.7251 \\
\hline 26 & 0.255955 & 0.684043 & 1.314972 & 1.705618 & 2.05553 & 2.47863 & 2.77871 & 3.7066 \\
\hline 27 & 0.255858 & 0.683685 & 1.313703 & 1.703288 & 2.05183 & 2.47266 & 2.77068 & 3.6896 \\
\hline 28 & 0.255768 & 0.683353 & 1.312527 & 1.701131 & 2.04841 & 2.46714 & 2.76326 & 3.6739 \\
\hline 29 & 0.255684 & 0.683044 & 1.311434 & 1.699127 & 2.04523 & 2.46202 & 2.75639 & 3.6594 \\
\hline 30 & 0.255605 & 0.682756 & 1.310415 & 1.697261 & 2.04227 & 2.45726 & 2.75000 & 3.6460 \\
\hline$z$ & 0.253347 & 0.674490 & 1.281552 & 1.644854 & 1.95996 & 2.32635 & 2.57583 & 3.2905 \\
\hline CI & & & $80 \%$ & $90 \%$ & $95 \%$ & $98 \%$ & $99 \%$ & $99.9 \%$ \\
\hline
\end{tabular}

Appendix 2

Frequencies (question 1)

\begin{tabular}{lll}
\hline \multicolumn{2}{l}{ Statistics } \\
\hline Q4a1 & \\
\hline $\mathrm{N}$ & Valid & 753 \\
\cline { 2 - 3 } & Missing & 10 \\
\hline
\end{tabular}

\begin{tabular}{|c|c|c|c|c|c|}
\hline \multicolumn{6}{|l|}{ Q4a1 } \\
\hline & & Frequency & Percent & Valid Percent & Cumulative Percent \\
\hline \multirow[t]{8}{*}{ Valid } & not at all important & 61 & 8.0 & 8.1 & 8.1 \\
\hline & $\overline{2}$ & 55 & 7.2 & 7.3 & 15.4 \\
\hline & 3 & 87 & 11.4 & 11.6 & 27.0 \\
\hline & $\overline{4}$ & 106 & 13.9 & 14.1 & 41.0 \\
\hline & 5 & 174 & 22.8 & 23.1 & 64.1 \\
\hline & 6 & 141 & 18.5 & 18.7 & 82.9 \\
\hline & very important & 129 & 16.9 & 17.1 & 100.0 \\
\hline & Total & 753 & 98.7 & 100.0 & \\
\hline Missing & System & 10 & 1.3 & & \\
\hline Total & & 763 & 100.0 & & \\
\hline
\end{tabular}


Paired Sample Test (question 2)

\section{Paired Samples Statistics}

\begin{tabular}{llllll}
\hline & & Mean & $\mathrm{N}$ & Std. Deviation & Std. Error Mean \\
\hline Pair 1 & Q2c6 & 4.41 & 753 & 1.683 & .061 \\
\cline { 2 - 6 } & Q2c7 & 2.82 & 753 & 1.598 & .058 \\
\hline
\end{tabular}

\section{Paired Samples Correlations}

\begin{tabular}{|c|c|c|c|c|c|c|}
\hline & & $\mathrm{N}$ & Correlation & \multicolumn{3}{|l|}{ Sig. } \\
\hline Pair 1 & Q2c6 \& Q2c7 & 753 & -.063 & \multicolumn{3}{|l|}{.083} \\
\hline \multicolumn{7}{|c|}{ Paired Samples Test } \\
\hline & & \multicolumn{5}{|c|}{ Paired Differences } \\
\hline & & \multirow[b]{2}{*}{ Mean } & \multirow[b]{2}{*}{ Std. Deviation } & \multirow[b]{2}{*}{ Std. Error Mean } & \multicolumn{2}{|c|}{$95 \%$ Confidence Interval of the Difference } \\
\hline & & & & & Lower & Upper \\
\hline Pair 1 & Q2c6 - Q2c7 & 1.584 & 2.393 & .087 & 1.413 & 1.755 \\
\hline
\end{tabular}

\section{Paired Samples Test}

\begin{tabular}{lllll} 
& & $\mathrm{t}$ & $\mathrm{df}$ & Sig. (2-tailed) \\
\hline Pair 1 & Q2c6- Q2c7 & 18.171 & 752 & .000 \\
\hline
\end{tabular}

Correlations (question 3)

\section{Correlations}

How likely would you be to encourage your friends and family

\begin{tabular}{|c|c|c|c|}
\hline & & Q4a4 & in Australia to donate blood? \\
\hline \multirow[t]{3}{*}{ Q4a4 } & Pearson Correlation & 1 & $-.240^{* *}$ \\
\hline & Sig. (2-tailed) & & .000 \\
\hline & $\mathrm{N}$ & 750 & 748 \\
\hline \multirow{3}{*}{$\begin{array}{l}\text { How likely would you be to encourage } \\
\text { your friends and family in Australia to } \\
\text { donate blood? }\end{array}$} & Pearson Correlation & $-.240^{* *}$ & 1 \\
\hline & Sig. (2-tailed) & .000 & \\
\hline & $\mathrm{N}$ & 748 & 761 \\
\hline
\end{tabular}

**. Correlation is significant at the 0.01 level (2-tailed).

Regression Analysis (question 4)

\begin{tabular}{lllll}
\hline \multicolumn{2}{l}{ Model Summary } & & & \\
\hline Model & $\mathrm{R}$ & R Square & Adjusted R Square & Std. Error of the Estimate \\
\hline 1 & $.289^{\mathrm{a}}$ & .084 & .079 & 1.741 \\
\hline a. Predictors: (Constant), Q4a10, Q4a5, Q4a14, Q4a4 & \\
\hline
\end{tabular}




\begin{tabular}{lllllll}
\hline ANOVA $^{\text {a }}$ & \multicolumn{7}{l}{} & & & \\
\hline Model & & Sum of Squares & df & Mean Square & F & Sig. \\
\hline 1 & Regression & 203.277 & 4 & 50.819 & 16.765 & $.000^{\mathrm{b}}$ \\
\hline & Residual & 2230.990 & 736 & 3.031 & & \\
\hline & Total & 2434.267 & 740 & & & \\
\hline
\end{tabular}

a. Dependent Variable: How likely would you be to encourage your friends and family in Australia to donate blood?

b. Predictors: (Constant), Q4a10, Q4a5, Q4a14, Q4a4

\section{Coefficients $^{\mathrm{a}}$}

\begin{tabular}{|c|c|c|c|c|c|c|}
\hline \multirow[b]{2}{*}{ Model } & & \multicolumn{2}{|c|}{ Unstandardized Coefficients } & \multirow{2}{*}{$\begin{array}{l}\text { Standardized } \\
\text { Coefficients } \\
\text { Beta }\end{array}$} & \multirow[b]{2}{*}{$\mathrm{t}$} & \multirow[b]{2}{*}{ Sig. } \\
\hline & & $\bar{B}$ & Std. Error & & & \\
\hline \multirow[t]{5}{*}{1} & (Constant) & 4.740 & .251 & & 18.857 & .000 \\
\hline & Q4a14 & -.153 & .039 & -.147 & -3.902 & .000 \\
\hline & Q4a5 & -.089 & .040 & -.089 & -2.251 & .025 \\
\hline & Q4a4 & -.157 & .038 & -.168 & -4.123 & .000 \\
\hline & Q4a10 & .063 & .040 & .058 & 1.579 & .115 \\
\hline
\end{tabular}

a. Dependent Variable: How likely would you be to encourage your friends and family in Australia to donate blood?

Regression Analysis (question 5)

\begin{tabular}{|c|c|c|c|c|}
\hline \multicolumn{5}{|c|}{ Model Summary } \\
\hline Model & $\mathrm{R}$ & R Square & Adjusted R Square & Std. Error of the Estimate \\
\hline 1 & $.284^{\mathrm{a}}$ & .081 & .076 & 1.229 \\
\hline
\end{tabular}

\begin{tabular}{|c|c|c|c|c|c|c|}
\hline$\overline{\text { ANOV }}$ & & & & & & \\
\hline Model & & Sum of Squares & $\mathrm{df}$ & Mean Square & $\mathrm{F}$ & Sig. \\
\hline 1 & Regression & 97.808 & 4 & 24.452 & 16.178 & $.000^{\mathrm{b}}$ \\
\hline & Residual & 1112.397 & 736 & 1.511 & & \\
\hline & $\overline{\text { Total }}$ & 1210.205 & 740 & & & \\
\hline a. Depe & dent Variable & In a typical year, $h$ & ow fr & y do you give ti & or mon & charity? \\
\hline b. Pred & ctors: (Consta & , Q3b14, Q3b10, & 23b6, & & & \\
\hline
\end{tabular}

\begin{tabular}{|c|c|c|c|c|c|c|}
\hline \multicolumn{7}{|c|}{ Coefficients $^{\mathrm{a}}$} \\
\hline \multirow[b]{2}{*}{ Model } & & Unsta & Coefficients & Standardized Coefficients & \multirow[b]{2}{*}{$\mathrm{t}$} & \multirow[b]{2}{*}{ Sig. } \\
\hline & & $\bar{B}$ & Std. Error & Beta & & \\
\hline \multirow[t]{5}{*}{1} & (Constant) & 1.121 & .203 & & 5.528 & .000 \\
\hline & Q3b2 & .143 & .035 & .157 & 4.082 & .000 \\
\hline & Q3b6 & -.152 & .032 & -.182 & -4.785 & .000 \\
\hline & Q3b10 & -.094 & .029 & -.119 & -3.228 & .001 \\
\hline & Q3b14 & .109 & .032 & .134 & 3.431 & .001 \\
\hline
\end{tabular}

a. Dependent Variable: In a typical year, how frequently do you give time or money to charity? 
Independent Sample Test (question 6)

(1=Male, 2=Female)

\section{Group Statistics}

\begin{tabular}{|c|c|c|c|c|c|}
\hline & gender & $\mathrm{N}$ & Mean & Std. Deviation & Std. Error Mean \\
\hline How many times have you donated any & 1.00 & 207 & .22 & 1.578 & .110 \\
\hline $\begin{array}{l}\text { blood products (for example, whole } \\
\text { blood, plasma, platelets) within } \\
\text { Australia in the last two years? }\end{array}$ & 2.00 & 466 & .09 & .704 & .033 \\
\hline
\end{tabular}

\section{Independent Samples Test}

Levene's Test for Equality t-test for Equality of of Variances Means

F

Sig. $\quad \mathrm{t}$

\begin{tabular}{llrlll}
\hline How many times have you donated Equal variances & 6.969 & .008 & 1.447
\end{tabular}

any blood products (for example, assumed

whole blood, plasma, platelets) within Equal variances

Australia in the last two years? not assumed

\section{Independent Samples Test}

\begin{tabular}{|c|c|c|c|}
\hline & \multicolumn{3}{|c|}{ t-test for Equality of Means } \\
\hline & \multirow{2}{*}{$\begin{array}{l}\text { Std. Error } \\
\text { Difference }\end{array}$} & $\begin{array}{l}95 \% \text { Confidence } \\
\text { Difference }\end{array}$ & Interval of the \\
\hline & & Lower & Upper \\
\hline $\begin{array}{l}\text { How many times have you donated Equal variances } \\
\text { any blood products (for example, assumed }\end{array}$ & .088 & -.045 & .300 \\
\hline $\begin{array}{l}\text { whole blood, plasma, platelets) within } \\
\text { Australia in the last two years? }\end{array}$ & .114 & -.098 & .353 \\
\hline
\end{tabular}

One Sample Test (question 7)

\section{One-Sample Test}

\begin{tabular}{|c|c|c|c|c|c|c|}
\hline & \multicolumn{6}{|c|}{ Test Value $=4$} \\
\hline & \multirow[b]{2}{*}{$\mathrm{t}$} & \multirow[b]{2}{*}{ df } & \multirow[b]{2}{*}{ Sig. (2-tailed) } & \multirow{2}{*}{$\begin{array}{l}\text { Mean } \\
\text { Difference }\end{array}$} & \multicolumn{2}{|c|}{$95 \%$ Confidence Interval of the Difference } \\
\hline & & & & & Lower & Upper \\
\hline Q3b11 & 27.976 & 752 & .000 & 1.456 & 1.35 & 1.56 \\
\hline
\end{tabular}

\section{Copyrights}

Copyright for this article is retained by the author(s), with first publication rights granted to the journal.

This is an open-access article distributed under the terms and conditions of the Creative Commons Attribution license (http://creativecommons.org/licenses/by/4.0/). 